\title{
Stability Analysis of Tuberculosis Spread Model in Diabetes Mellitus Patients with Treatment Factor
}

\section{Analisis Kestabilan Model Penyebaran Penyakit Tuberkulosis pada Penderita Diabetes Mellitus dengan Faktor Pengobatan}

\author{
Nursamsi $^{1 *}$, Syamsuddin Toaha ${ }^{2 *}$, Kasbawati $^{3 *}$
}

\begin{abstract}
Diabetes mellitus (Dm) is a disease associated with impaired immune function so it is more susceptible to get infections including Tuberculosis (Tb). Tb disease can also worsen blood sugar levels which can cause Dm disease. This study aims to analyze and determine the stability of the equilibrium point of the spread of Tb disease in patients with Dm with consideration nine compartments, which are susceptible Tb without Dm, susceptible Tb without Dm complication, susceptible Tb with Dm complication, expose Tb without Dm, expose Tb with Dm, infected Tb without Dm, infected Tb with Dm, recovered Tb without Dm, and recovered Tb with Dm with treatment factors. The result obtained from the analysis of the model is two equilibrium points, which are the non endemic and endemic equilibrium points. The endemic equilibrium point does not exist if $\mathcal{R}_{0}<1$, endemic will appear if $\mathcal{R}_{0}>1$. Analytical and numerical simulation show that the spread of disease can be reduced and stopped if treatment is given to the infected compartment.
\end{abstract}

Keywords: Tuberculosis, Diabetes mellitus, Equilibrium Point.

\begin{abstract}
Abstrak
Diabetes mellitus (Dm) merupakan penyakit yang berkaitan dengan gangguan fungsi imunitas tubuh sehingga lebih rentan terserang infeksi termasuk penyakit Tuberkulosis ( $\mathrm{Tb}$ ). Penyakit $\mathrm{Tb}$ juga dapat memperburuk kadar gula darah yang dapat menyebabkan penyakit Dm. Penelitian ini bertujuan untuk menganalisis dan menentukan kestabilan titik kesetimbangan dari model penyebaran penyakit Tb pada penderita Dm yang mempertimbangkan sembilan kompartemen yaitu susceptible Tb without Dm, susceptible Tb without Dm complication, susceptible Tb with Dm complication, expose Tb without Dm, expose Tb with Dm, infected Tb without Dm, infected Tb with $\mathrm{Dm}$, recovered $\mathrm{Tb}$ without $\mathrm{Dm}$, dan recovered $\mathrm{Tb}$ with $\mathrm{Dm}$ dengan faktor pengobatan. Hasil yang diperoleh dari analisis model terdapat dua titik kesetimbangan, yaitu titik kesetimbangan non endemik dan endemik. Titik kesetimbangan endemik tidak ada jika $\mathcal{R}_{0}<1$, endemik akan muncul jika $\mathcal{R}_{0}>1$. Secara analitik dan simulasi numerik menunjukkan bahwa penyebaran penyakit dapat dikurangi dan dihilangkan jika diberikan pengobatan pada kompartemen yang terinfeksi.
\end{abstract}

Kata kunci:. Tuberkulosis, Diabetes Mellitus, Titik Kesetimbangan.

\section{Pendahuluan}

Model matematika telah digunakan secara meluas sebagai suatu metode pendekatan untuk mengenali dengan baik mekanisme penyebaran suatu penyakit menular. Wiraningsih ([1], [2]) telah mengkaji dan menganalisis dinamika penyebaran penyakit rabies pada anjing yang mempertimbangkan vaksin dan pengobatan dalam upaya menangani laju penyebaran penyakit

\footnotetext{
* Program Studi Magister Matematika, FMIPA-UNHAS

Email: ${ }^{1}$ ancynursyamsi@yahoo.com, ${ }^{2}$ syamsuddint@gmail.com, ${ }^{3}$ kasbawati@gmail.com
} 
rabies. Suatu model bagaimana penyakit malaria menyebar dengan menggunakan berbagai modifikasi model SIR telah dikaji oleh Beay [3] dengan melibatkan pengaruh migrasi dalam mekanisme modelnya. Sementara Hartati [4] mengambil vaksin dan penggunaan insektisida untuk mengendalikan penyakit malaria. Muin [5] menganalisis suatu modifikasi model SEIR untuk mengetahui penyebaran penyakit hepatitis dengan mengambil vaksin dan pengobatan kepada kelompok yang masuk sebagai penyakit hepatitis.

Tuberkulosis $(\mathrm{Tb})$ merupakan penyakit menular pada paru-paru yang disebabkan oleh bakteri Mycobacterium tuberculosis (mtb) yang ditularkan melalui percikan ludah dari individu ke individu yang terinfeksi mtb, tubuh yang memiliki kekebalan atau imunitas yang baik tentu dapat menghalangi perkembangan kuman sehingga masih berada dalam fase $\mathrm{Tb}$ laten (terinfeksi $\mathrm{Tb}$ namun tidak berpotensi menularkan kuman $\mathrm{Tb}$ ), sebaliknya bila kekebalan tubuh rendah maka kuman akan berkembang lebih cepat menjadi Tb aktif (terinfeksi Tb dan berpotensi menularkan kuman Tb) serta menyerang organ ([6], [7]). Resiko Tb aktif meningkat pada penderita Dm yaitu kadar gula darah tidak terkendali dengan adanya gangguan dari respon imun pada penderita Dm [8]. Diabetes mellitus (Dm) merupakan kumpulan gejala yang timbul pada seseorang akibat gula darah yang tinggi (hiperglikemia) dan menyebabkan komplikasi akibat gula darah tidak terkendali [9]. Penelitian menunjukkan bahwa Dm dapat menekan respon imun yang memfasilitasi bakteri Mycobacterium tuberculosis (mtb) dan dapat berkembang menjadi penyakit simtomatik. Hal ini diperkuat oleh fakta Dm umumnya didiagnosis sebelum tuberkulosis berkembang [10].

Penyebaran penyakit Tb pada penderita Dm menarik untuk dikaji melalui model matematika. Model matematika dapat memprediksi dan mengendalikan penyebaran Tb pada penderita Dm maupun tanpa Dm di masa yang akan datang. Moualeu dkk [11] mengkaji model penyebaran $\mathrm{Tb}$ serta dampak $\mathrm{Dm}$ terhadap epidemi $\mathrm{Tb}$ yang membagi populasi menjadi delapan kompartemen yaitu susceptible $\mathrm{Tb}$ without $\mathrm{Dm}$, susceptible Tb with $\mathrm{Dm}$, expose Tb without Dm, expose Tb with Dm, infected Tb without Dm, infected Tb with Dm, recovered $\mathrm{Tb}$ without $\mathrm{Dm}$, dan recovered $\mathrm{Tb}$ with $\mathrm{Dm}$. Danumjaya dan Merina [12] memodelkan penyebaran penyakit Dm dan Tb dengan mempertimbangkan tiga kompartemen yaitu Dm without complication (D), Dm with complication $(C)$, dan Dm with complication and Infected $\mathrm{Tb}(T)$.

\section{Model Penyebaran Penyakit Tuberkulosis}

Pada tulisan ini, populasi manusia dibagi menjadi sembilan kompartemen dengan membedakan kompartemen susceptible Tb without Dm complication $\left(S_{2}\right)$ dan susceptible Tb with Dm complication $\left(S_{3}\right)$, serta mengklasifikasikan populasi ke dalam kompartemen $\mathrm{Tb}$ tanpa Dm namun berpotensi terkena Dm pada indeks 1 dan kompartemen Tb dengan Dm pada indeks 2 seperti yang diberikan oleh [11]. Diasumsikan bahwa individu yang rentan mendapat infeksi Tb dari individu dengan Tb aktif dengan laju $\lambda=\beta \frac{I_{1}+\varepsilon I_{2}}{N}$, di mana $\beta$ tingkat kontak efektif yang dapat menularkan infeksi pada individu rentan Tb dengan dan tanpa terkena Dm. Parameter modifikasi $\varepsilon>1$ mengukur tingginya laju infeksi Tb dengan Dm yang berada pada kompartemen $I_{2}$. Diasumsikan pula bahwa setiap individu yang lahir adalah sehat dan rentan $\mathrm{Tb}$, kemudian masuk ke dalam kompartemen $S_{1}$ dengan laju $\Lambda$.

Individu dalam kompartemen $S_{1}$ diasumsikan ketika tubuh telah didiami oleh bakteri Tb, kompartemen $S_{1}$ dapat menjadi Tb aktif sehingga dapat berpindah ke kompartemen $I_{1}$ dengan laju $p_{1} \lambda$. Namun dengan adanya sistem kekebalan tubuh, kompartemen $S_{1}$ dapat berpindah ke kompartemen $E_{1}$ dengan laju $\left(1-p_{1}\right) \lambda$. Diasumsikan pula bahwa yang rentan Tb dapat berpindah ke kompartemen $S_{2}$ dan $S_{3}$ dengan laju masing-masing $q$ dan $(1-q)$. Kompartemen $E_{1}$ ketika tubuh terkena bakteri Tb yang belum aktif atau berada dalam fase $\mathrm{Tb}$ laten dan tidak dilakukan pengobatan dapat berpindah ke kompartemen $I_{1}$ dengan laju $\left(1-r_{1}\right)\left(k_{1}+\sigma_{1} \lambda\right)$ dan dapat berpindah pula ke kompartemen $E_{2}$ dengan laju $\alpha$. Individu dalam kompartemen $I_{1}$ diasumsikan tidak memiliki pemulihan alami kecuali diberikan pengobatan kemudian dapat berpindah ke $R_{1}$ dengan laju $\gamma_{1}$. Diasumsikan pula bahwa pada 
kompartemen $I_{1}$ apabila gula darah yang tidak terkendali, ia dapat berpindah ke $I_{2}$ dengan laju $\tau \alpha$. Individu dalam kompartemen $R_{1}$ tidak mendapat kekebalan permanen karena adanya kuman yang masih tersisa dari infeksi sebelumnya yang dapat berkembang kembali atau adanya infeksi baru sehingga dapat berpindah ke $I_{1}$ dengan laju $\delta_{1}$ dan berpindah kembali ke $E_{1}$ dengan laju $\sigma_{3}\left(1-\delta_{1}\right) \lambda$. Kompartemen $R_{1}$ dapat berpindah ke $R_{2}$ dengan laju $\alpha$.

Individu dalam $S_{2}$ diasumsikan kadar gula darah tinggi yang tidak terkendali dapat menyebabkan komplikasi sehingga berpindah ke kompartemen $S_{3}$ dengan laju $\left(1-p_{2}\right)$ dan kadar gula melemahkan sistem kekabalan imun yang terinfeksi Tb sehingga dapat berpindah ke kompartemen $I_{2}$ dengan laju $\theta p_{2} \lambda$. Kompartemen $S_{3}$ diasumsikan terinfeksi Tb yang cepat melemahkan sistem kekebalan tubuh (Tb aktif) pada penderita Dm sehingga berpindah ke kompartemen $I_{2}$ denga laju $\theta p_{3} \lambda$. Ketika penderita Dm dengan kekebalan tubuh yang masih baik, $S_{3}$ dapat berpindah ke $E_{2}$ dengan laju $\theta\left(1-p_{3}\right) \lambda$. Individu dalam kompartemen $E_{2}$, yaitu ketika penderita $\mathrm{Dm}$ yang terpapar Tb laten dan tidak dilakukan pengobatan, dapat berpindah ke kompartemen $I_{2}$ dengan laju $\left(1-r_{2}\right)\left(k_{2}+\sigma_{2} \lambda\right)$. Diasumsikan pula bahwa kompartemen $I_{2}$ tidak memiliki pemulihan alami kecuali diberikan pengobatan sehingga dapat berpindah ke $R_{2}$ dengan laju $\gamma_{2}$. Kompartemen $R_{2}$ tidak mendapat kekebalan permanen sehingga ia dapat berpindah kembali ke $I_{2}$ dengan laju $\delta_{2}$ atau dipengaruhi adanya infeksi baru sehingga ia dapat berpindah ke $E_{2}$ dengan laju $\sigma_{4} \theta\left(1-\delta_{4}\right) \lambda$. Pada setiap kompartemen diasumsikan mengalami kematian alami dengan laju $\mu$. Dengan asumsi yang diberikan, dinamika penyebaran penyakit tuberculosis dinyatakan dalam sistem berikut

$$
\begin{gathered}
\frac{d S_{1}(t)}{d t}=\Lambda-(1+\lambda+\mu) S_{1}, \\
\frac{d S_{2}(t)}{d t}=q S_{1}-\left(\left(1-p_{2}\right)+\theta p_{2} \lambda+\mu\right) S_{2}, \\
\frac{d S_{3}(t)}{d t}=(1-q) S_{1}+\left(1-p_{2}\right) S_{2}-\theta\left(1-p_{3}\right) \lambda S_{3}-\theta p_{3} \lambda S_{3}-\mu S_{3}, \\
\frac{d E_{1}(t)}{d t}=\left(1-p_{1}\right) \lambda S_{1}+\sigma_{3}\left(1-\delta_{1}\right) \lambda R_{1}-\left(1-r_{1}\right)\left(k_{1}+\sigma_{1} \lambda\right) E_{1}-(\alpha+\mu) E_{1}, \\
\frac{d E_{2}(t)}{d t}=\theta\left(1-p_{3}\right) \lambda S_{3}+\alpha E_{1}+\sigma_{4} \theta\left(1-\delta_{2}\right) \lambda R_{2}-\left(1-r_{2}\right)\left(k_{2}+\sigma_{2} \lambda\right) E_{2}-\mu E_{2}, \\
\frac{d I_{1}(t)}{d t}=p_{1} \lambda S_{1}+\left(1-r_{1}\right)\left(k_{1}+\sigma_{1} \lambda\right) E_{1}+\delta_{1} R_{1}-\left(\gamma_{1}+\alpha \tau+\mu\right) I_{1}, \\
\frac{d I_{2}(t)}{d t}=\theta p_{2} \lambda S_{2}+\theta p_{3} \lambda S_{3}+\left(1-r_{2}\right)\left(k_{2}+\sigma_{2} \lambda\right) E_{2}+\alpha \tau I_{1}+\delta_{1} R_{2}-\left(\gamma_{2}+\mu\right) I_{2}, \\
\frac{d R_{1}(t)}{d t}=\gamma_{1} I_{1}-\sigma_{3}\left(1-\delta_{1}\right) \lambda R_{1}-\left(\delta_{1}+\alpha+\mu\right) R_{1}, \\
\frac{d R_{2}(t)}{d t}=\gamma_{2} I_{2}+\alpha R_{1}-\sigma_{4} \theta\left(1-\delta_{2}\right) \lambda R_{2}-\left(\delta_{2}+\mu\right) R_{2} .
\end{gathered}
$$

di mana $\lambda=\beta\left(\frac{I_{1}+\varepsilon I_{2}}{N}\right)$.

Keterangan mengenai satuan dari semua variabel dan parameter diberikan secara ringkas dalam Tabel 2.1.

Tabel 2.1. Keterangan Variabel dan Parameter Model dalam Sistem (2.1), lihat [11].

\begin{tabular}{clc}
\hline $\begin{array}{c}\text { Variabel/ } \\
\text { Parameter }\end{array}$ & \multicolumn{1}{c}{ Deskripsi } & Nilai \\
\hline$S_{1}$ & Jumlah populasi rentan Tb tanpa Dm & - \\
$E_{1}$ & Jumlah populasi terpapar Tb tanpa Dm & - \\
$I_{1}$ & Jumlah populasi terinfeksi Tb tanpa Dm & - \\
$R_{1}$ & Jumlah populasi pulih sementara yang Tb tanpa Dm & - \\
$S_{2}$ & Jumlah populasi rentan Tb tanpa komplikasi Dm & - \\
$S_{3}$ & Jumlah populasi rentan Tb yang komplikasi Dm & - \\
$E_{2}$ & Jumlah populasi terpapar Tb yang menderita Dm & - \\
$I_{2}$ & Jumlah populasi terinfeksi Tb yang menderita Dm & - \\
$R_{2}$ & Jumlah populasi pullih sementara Tb yang terkena Dm & - \\
$\mu$ & Laju kematian alami & 1.5
\end{tabular}


$q \quad$ Laju perpindahan dari individu yang rentan $S_{1}$

$\beta \quad$ Tingkat kontak efektif menularkan infeksi yang rentan Tb dengan dan tanpa terkena Dm

$\begin{array}{ll}p_{1} & \text { Laju Tb aktif yang berkembang lebih cepat dari kompartemen } S_{1} \\ p_{2} & \text { Laju Tb aktif yang berkembang lebih cepat dari kompartemen } S_{2}\end{array}$

$p_{3} \quad$ Laju Tb aktif yang berkembang lebih cepat dari kompartemen $S_{3}$

Laju individu yang terinfeksi mtb

$k_{1} \quad$ Laju reaktivitas endogen yang terpapar Tb tanpa Dm

$k_{2} \quad$ Laju reaktivitas endogen yang terpapar Tb yang menderita Dm

\section{Hasil dan Pembahasan}

Ukuran populasi total pada persamaan (2.1) dinyatakan sebagai $N(t)=S_{1}(t)+S_{2}(t)+$ $S_{3}(t)+E_{1}(t)+E_{2}(t)+I_{1}(t)+I_{2}(t)+R_{1}(t)+R_{2}$. Dengan itu, persamaan (2.1) dapat disederhanakan dalam bentuk proporsi subpopulasi dengan banyaknya populasi total. Untuk itu, dimisalkan $x_{1}=\frac{S_{1}(t)}{N(t)}, x_{2}=\frac{S_{2}(t)}{N(t)}, x_{3}=\frac{S_{3}(t)}{N(t)}, x_{4}=\frac{E_{1}(t)}{N(t)}, x_{5}=\frac{E_{2}(t)}{N(t)}, x_{6}=\frac{I_{1}(t)}{N(t)}, x_{7}=$ $\frac{I_{2}(t)}{N(t)}, x_{8}=\frac{R_{1}(t)}{N(t)}, x_{9}=\frac{R_{2}(t)}{N(t)}$. Kemudian disubstitusi ke persamaan (2.1) dan diperoleh

$$
\begin{gathered}
\frac{d x_{1}}{d t}=\mu-(1+\lambda+\mu) x_{1}, \\
\frac{d x_{2}}{d t}=q x_{1}-\left(\left(1-p_{2}\right)+\theta p_{2} \lambda+\mu\right) x_{2}, \\
\frac{d x_{3}}{d t}=(1-q) x_{1}+\left(1-p_{2}\right) x_{2}-\theta\left(1-p_{3}\right) \lambda x_{3}-\theta p_{3} \lambda x_{3}-\mu x_{3}, \\
\frac{d x_{4}}{d t}=\left(1-p_{1}\right) \lambda x_{1}+\sigma_{3}\left(1-\delta_{1}\right) \lambda x_{8}-\left(1-r_{1}\right)\left(k_{1}+\sigma_{1} \lambda\right) x_{4}-(\alpha+\mu) x_{4}, \\
\frac{d x_{5}}{d t}=\theta\left(1-p_{3}\right) \lambda x_{3}+\alpha x_{4}+\sigma_{4} \theta\left(1-\delta_{2}\right) \lambda x_{9}-\left(1-r_{2}\right)\left(k_{2}+\sigma_{2} \lambda\right) x_{5}-\mu x_{5}, \\
\frac{d x_{6}}{d t}=p_{1} \lambda x_{1}+\left(1-r_{1}\right)\left(k_{1}+\sigma_{1} \lambda\right) x_{4}+\delta_{1} x_{8}-\left(\gamma_{1}+\alpha \tau+\mu\right) x_{6}, \\
\frac{d x_{7}}{d t}=\theta p_{2} \lambda x_{2}+\theta p_{3} \lambda x_{3}+\left(1-r_{2}\right)\left(k_{2}+\sigma_{2} \lambda\right) x_{5}+\alpha \tau x_{6}+\delta_{2} x_{9}-\left(\gamma_{2}+\mu\right) x_{7}, \\
\frac{d x_{8}}{d t}=\gamma_{1} x_{6}-\sigma_{3}\left(1-\delta_{1}\right) \lambda x_{8}-\left(\delta_{1}+\alpha+\mu\right) x_{8}, \\
\frac{d x_{9}}{d t}=\gamma_{2} x_{7}+\alpha x_{8}-\sigma_{4} \theta\left(1-\delta_{2}\right) \lambda x_{9}-\left(\delta_{2}+\mu\right) x_{9},
\end{gathered}
$$

di mana $\lambda=\beta\left(x_{6}+\varepsilon x_{7}\right)$.

Persamaan (3.1) merupakan sistem non linear dan pada sistem tersebut analisis hanya difokuskan pada perilaku sistem di sekitar titik-titik kesetimbangan dari model. Untuk itu, model dilinearkan di sekitar titik kesetimbangan dengan menggunakan variasi pertama dari sistem melalui matriks Jacobi 


$$
J=\left(\begin{array}{ccccccccc}
-y_{1} & 0 & 0 & 0 & 0 & 0 & 0 & 0 & 0 \\
q & -y_{2} & 0 & 0 & 0 & 0 & 0 & 0 & 0 \\
(1-q) & \left(1-p_{2}\right) & -y_{3} & 0 & 0 & 0 & 0 & 0 & 0 \\
y_{10} & 0 & 0 & -y_{4} & 0 & 0 & 0 & y_{14} & 0 \\
0 & 0 & y_{11} & \alpha & -y_{5} & 0 & 0 & 0 & y_{15} \\
p_{1} \lambda & 0 & 0 & y_{12} & 0 & -y_{6} & 0 & \delta_{1} & 0 \\
0 & \theta p_{2} \lambda & \theta p_{3} \lambda & 0 & y_{13} & \alpha \tau & -y_{7} & 0 & \delta_{2} \\
0 & 0 & 0 & 0 & 0 & \gamma_{1} & 0 & -y_{8} & 0 \\
0 & 0 & 0 & 0 & 0 & 0 & \gamma_{2} & \alpha & -y_{9}
\end{array}\right),
$$

di mana $y_{1}=(1+\lambda+\mu), y_{2}=\left(\left(1-p_{2}\right)+\theta p_{2} \lambda+\mu\right), y_{3}=\left(\theta\left(1-p_{3}\right) \lambda+\theta p_{3} \lambda+\mu\right)$, $y_{4}=\left(\left(1-r_{1}\right)\left(k_{1}+\sigma_{1} \lambda\right)+(\alpha+\mu)\right), y_{5}=\left(\left(1-r_{2}\right)\left(k_{2}+\sigma_{2} \lambda\right)+\mu\right), y_{6}=\left(\gamma_{1}+\alpha \tau+\mu\right)$, $y_{7}=\left(\gamma_{2}+\mu\right), \quad y_{8}=\left(\sigma_{3}\left(1-\delta_{1}\right) \lambda+\left(\delta_{1}+\alpha+\mu\right)\right), \quad y_{9}=\left(\sigma_{4} \theta\left(1-\delta_{2}\right) \lambda+\left(\delta_{2}+\mu\right)\right)$, $y_{10}=\left(1-p_{1}\right) \lambda, y_{11}=\theta\left(1-p_{3}\right) \lambda, y_{12}=\left(1-r_{1}\right)\left(k_{1}+\sigma_{1} \lambda\right), y_{13}=\left(1-r_{2}\right)\left(k_{2}+\sigma_{2} \lambda\right)$, $y_{14}=\sigma_{3}\left(1-\delta_{1}\right) \lambda, y_{15}=\sigma_{4} \theta\left(1-\delta_{2}\right) \lambda$.

Sistem (3.1) akan dianalisis dengan menentukan titik kesetimbangan non endemik dan endemik. Titik kesetimbangan sistem persamaan (3.1) dicapai ketika $\frac{d x_{1}}{d t}=0, \frac{d x_{2}}{d t}=0, \frac{d x_{3}}{d t}=$ $0, \frac{d x_{4}}{d t}=0, \frac{d x_{5}}{d t}=0, \frac{d x_{6}}{d t}=0, \frac{d x_{7}}{d t}=0, \frac{d x_{8}}{d t}=0, \frac{d x_{9}}{d t}=0$. Selanjutnya diperoleh

$$
\begin{gathered}
\mu-(1+\lambda+\mu) x_{1}=0, \\
q x_{1}-\left(\left(1-p_{2}\right)+\theta p_{2} \lambda+\mu\right) x_{2}=0, \\
(1-q) x_{1}+\left(1-p_{2}\right) x_{2}-\theta\left(1-p_{3}\right) \lambda x_{3}-\theta p_{3} \lambda x_{3}-\mu x_{3}=0, \\
\left(1-p_{1}\right) \lambda x_{1}+\sigma_{3}\left(1-\delta_{1}\right) \lambda x_{8}-\left(1-r_{1}\right)\left(k_{1}+\sigma_{1} \lambda\right) x_{4}-(\alpha+\mu) x_{4}=0, \\
\theta\left(1-p_{3}\right) \lambda x_{3}+\alpha x_{4}+\sigma_{4} \theta\left(1-\delta_{2}\right) \lambda x_{9}-\left(1-r_{2}\right)\left(k_{2}+\sigma_{2} \lambda\right) x_{5}-\mu x_{5}=0, \\
p_{1} \lambda x_{1}+\left(1-r_{1}\right)\left(k_{1}+\sigma_{1} \lambda\right) x_{4}+\delta_{1} x_{8}-\left(\gamma_{1}+\alpha \tau+\mu\right) x_{6}=0, \\
\theta p_{2} \lambda x_{2}+\theta p_{3} \lambda x_{3}+\left(1-r_{2}\right)\left(k_{2}+\sigma_{2} \lambda\right) x_{5}+\alpha \tau x_{6}+\delta_{2} x_{9}-\left(\gamma_{2}+\mu\right) x_{7}=0, \\
\gamma_{1} x_{6}-\sigma_{3}\left(1-\delta_{1}\right) \lambda x_{8}-\left(\delta_{1}+\alpha+\mu\right) x_{8}=0, \\
\gamma_{2} x_{7}+\alpha x_{8}-\sigma_{4} \theta\left(1-\delta_{2}\right) \lambda x_{9}-\left(\delta_{2}+\mu\right) x_{9}=0 .
\end{gathered}
$$

Titik kesetimbangan non endemik merupakan keadaan saat penyakit Tb yang menderita Dm tidak menyebar dalam suatu populasi dan terjadi saat $x_{4}=x_{5}=x_{6}=x_{7}=0$. Karena $x_{6}=0$ dan $x_{7}=0$ maka $\lambda=0$. Dengan itu, diperoleh titik kesetimbangan non endemik

$$
\begin{aligned}
\Sigma_{0} & =\left(x_{1_{0}}, x_{2_{0}}, x_{3_{0}}, x_{4_{0}}, x_{5_{0}}, x_{6_{0}}, x_{7_{0}}, x_{8_{0}}, x_{9_{0}}\right) \\
& =\left(\frac{\mu}{(1+\mu)}, \frac{q \mu}{(1+\mu)\left(1-p_{2}\right)+\mu}, \frac{((1-q)+q \mu)(1+\mu)\left(1-p_{2}\right)+(1-q) \mu^{2}}{\left((1+\mu)\left(1-p_{2}\right)+\mu\right)(1+\mu) \mu}, 0,0,0,0,0,0\right) .
\end{aligned}
$$

Titik kesetimbangan endemik merupakan keadaan di mana penyakit tuberkulosis menyebar dalam suatu populasi dan terjadi pada saat $x_{4}>0$ dan $x_{5}>0$ maka $x_{6}, x_{7}, x_{8}, x_{9}>0$. Dengan demikian diperoleh $\Sigma_{1}=\left(x_{1_{1}}, x_{2_{1}}, x_{3_{1}}, x_{4_{1}}, x_{5_{1}}, x_{6_{1}}, x_{7_{1}}, x_{8_{1}}, x_{9_{1}}\right)$.

Matriks Jacobi yang dievaluasi pada titik kesetimbangan $\left(\Sigma_{0}\right)$ dan $\left(\Sigma_{1}\right)$ diberikan sebagai

$$
J \Sigma_{0}=\left(\begin{array}{ccccccccc}
-a & 0 & 0 & 0 & 0 & 0 & 0 & 0 & 0 \\
q & -b & 0 & 0 & 0 & 0 & 0 & 0 & 0 \\
z_{1} & z_{2} & \mu & 0 & 0 & 0 & 0 & 0 & 0 \\
0 & 0 & 0 & -c & 0 & 0 & 0 & 0 & 0 \\
0 & 0 & 0 & \alpha & -d & 0 & 0 & 0 & 0 \\
0 & 0 & 0 & z_{3} & 0 & -e & 0 & \delta_{1} & 0 \\
0 & 0 & 0 & 0 & z_{4} & z_{5} & -f & 0 & \delta_{2} \\
0 & 0 & 0 & 0 & 0 & \gamma_{1} & 0 & -g & 0 \\
0 & 0 & 0 & 0 & 0 & 0 & \gamma_{2} & \alpha & -h
\end{array}\right) \quad J \Sigma_{1}=\left(\begin{array}{ccccccccc}
-m & 0 & 0 & 0 & 0 & 0 & 0 & 0 & 0 \\
q & -n & 0 & 0 & 0 & 0 & 0 & 0 & 0 \\
z_{1} & z_{4} & -s & 0 & 0 & 0 & 0 & 0 & 0 \\
z_{2} & 0 & 0 & -t & 0 & 0 & 0 & z_{11} & 0 \\
0 & 0 & z_{6} & \alpha & -u & 0 & 0 & 0 & z_{12} \\
z_{3} & 0 & 0 & z_{8} & 0 & -v & 0 & \delta_{1} & 0 \\
0 & Z_{5} & z_{7} & 0 & z_{9} & z_{10} & -w & 0 & \delta_{2} \\
0 & 0 & 0 & 0 & 0 & \gamma_{1} & 0 & -x & 0 \\
0 & 0 & 0 & 0 & 0 & 0 & \gamma_{2} & \alpha & -y
\end{array}\right)
$$


di mana $a=(1+\mu), b=\left(1-p_{2}\right)+\mu, c=\mu, d=\left(1-r_{1}\right) k_{1}+(\alpha+\mu), \quad e=$ $\left(1-r_{2}\right) k_{2}+\mu, f=\left(\gamma_{1}+\alpha \tau+\mu\right), g=\left(\gamma_{2}+\mu\right), h=\left(\delta_{1}+\alpha+\mu\right), j=\left(\delta_{2}+\mu\right), \quad z_{1}=$ $(1-q), \quad z_{2}=\left(1-p_{2}\right), \quad z_{3}=\left(1-r_{1}\right) k_{1}, \quad z_{4}=\left(1-r_{2}\right) k_{2}, \quad z_{5}=\alpha \tau, \quad m=(1+\lambda+\mu)$, $n=\left(1-p_{2}\right)+\theta p_{2} \lambda+\mu, s=\theta\left(1-p_{3}\right) \lambda+\theta p_{3} \lambda+\mu, t=\left(1-r_{1}\right)\left(k_{1}+\sigma_{1} \lambda\right)+(\alpha+\mu)$, $u=\left(1-r_{2}\right),\left(k_{2}+\sigma_{2} \lambda\right)+\mu, \quad v=\left(\gamma_{1}+\alpha \tau+\mu\right), \quad w=\left(\gamma_{2}+\mu\right), \quad x=\sigma_{3}\left(1-\delta_{1}\right) \lambda+$ $\left(\delta_{1}+\alpha+\mu\right), \quad y=\sigma_{4} \theta\left(1-\delta_{2}\right) \lambda+\left(\delta_{2}+\mu\right), \quad z_{1}=(1-q), \quad z_{2}=\left(1-p_{1}\right) \lambda, z_{3}=p_{1} \lambda$, $z_{4}=\left(1-p_{2}\right), z_{5}=\theta p_{2} \lambda, z_{6}=\theta\left(1-p_{3}\right) \lambda, z_{7}=\theta p_{3} \lambda, z_{8}=\left(1-r_{1}\right)\left(k_{1}+\sigma_{1} \lambda\right), z_{9}=$ $\left(1-r_{2}\right)\left(k_{2}+\sigma_{2} \lambda\right), z_{10}=\alpha \tau, z_{11}=\sigma_{3}\left(1-\delta_{1}\right) \lambda$, dan $z_{12}=\sigma_{4} \theta\left(1-\delta_{2}\right) \lambda$.

Dari matriks Jacobi $J \Sigma_{0}$ diperoleh dari persamaan karakteristik $\operatorname{det}\left(J \Sigma_{0}-\lambda I\right)=0$, yaitu

$$
\lambda^{9}+A_{1} \lambda^{8}+A_{2} \lambda^{7}+A_{3} \lambda^{6}+A_{4} \lambda^{5}+A_{5} \lambda^{4}+A_{6} \lambda^{3}+A_{7} \lambda^{2}+A_{8} \lambda^{1}+A_{9}=0 .
$$

Akar-akar dari persamaan karakteristik (3.5) tidak mudah diperoleh secara eksplisit karena melibatkan banyak parameter di dalamnya. Dalam analisis ini, uji kestabilan Routh-Hurwitz akan diterapkan untuk mengetahui kestabilan titik kesetimbangan sistem. Uji kestabilan Routh-Hurwitz mengacu kepada koefisien dari persamaan karakteristik (3.5), di mana semua akar-akar bagian realnya bernilai negatif jika dan hanya jika syarat-syarat dari uji RouthHurwitz dipenuhi, lihat ([13], [14], [15]).

Suatu model biasanya memiliki parameter threshold atau bilangan reproduksi dasar $\left(\mathcal{R}_{0}\right)$. Ketika nilai $\mathcal{R}_{0}<1$ maka titik kesetimbangan non endemik suatu sistem stabil asimtotik lokal dan penyakit dalam populasi tersebut akan menghilang. Dalam kasus nilai $\mathcal{R}_{0}>1$ maka titik kesetimbangan non endemik tidak stabil dan titik kesetimbangan endemik muncul dan stabil yang bermakna bahwa penyakit akan tetap menyebar dalam populasi dan terjadi epidemik [16]. Nilai $\mathcal{R}_{0}$ dapat diperoleh dengan menggunakan metode matriks next generasi. Dalam proses pencarian nilai $\mathcal{R}_{0}$ dimisalkan $\mathcal{F}_{i}(x)$ adalah laju penambahan infeksi baru pada kompartemen $i$ dan $\mathcal{V}_{i}(x)$ adalah laju perpindahan individu pada kompartemen $i$. Dengan demikian dari persamaan (3.1) diperoleh matriks $\mathcal{F}_{i}(x)$ dan $\mathcal{V}_{i}(x)$ sebagai berikut

$$
\begin{gathered}
\mathcal{F}(x)=\left(\begin{array}{c}
\left(1-p_{1}\right) \lambda x_{1} \\
p_{1} \lambda x_{1} \\
0 \\
\theta\left(1-p_{3}\right) \lambda x_{3} \\
\theta p_{2} \lambda x_{2}+\theta p_{3} \lambda x_{3} \\
0
\end{array}\right), \\
v(x)=\left(\begin{array}{c}
-\sigma_{3}\left(1-\delta_{1}\right) \lambda x_{8}+\left(1-r_{1}\right)\left(k_{1}+\sigma_{1} \lambda\right) x_{4}+(\alpha+\mu) x_{4} \\
-\left(1-r_{1}\right)\left(k_{1}+\sigma_{1} \lambda\right) x_{4}-\delta_{1} x_{8}+\left(\gamma_{1}+\alpha \tau+\mu\right) x_{6} \\
-\gamma_{1} x_{6}+\sigma_{3}\left(1-\delta_{1}\right) \lambda x_{8}+\left(\delta_{1}+\alpha+\mu\right) x_{8} \\
-\alpha x_{4}-\sigma_{4} \theta\left(1-\delta_{2}\right) \lambda x_{9}+\left(1-r_{2}\right)\left(k_{2}+\sigma_{2} \lambda\right) x_{5}+\mu x_{5} \\
-\left(1-r_{2}\right)\left(k_{2}+\sigma_{2} \lambda\right) x_{5}-\alpha \tau x_{6}-\delta_{1} x_{9}+\left(\gamma_{2}+\mu\right) x_{7} \\
-\gamma_{2} x_{7}-\alpha x_{8}+\sigma_{4} \theta\left(1-\delta_{2}\right) \lambda x_{9}+\left(\delta_{2}+\mu\right) x_{9}
\end{array}\right) .
\end{gathered}
$$

Selanjutnya, dari persamaan (3.6) dan (3.7) diperoleh matriks

$$
F=\frac{\partial \mathcal{F}_{i}\left(\Sigma_{0}\right)}{\partial x_{j}}=\left(\begin{array}{cccccc}
0 & b_{1} \beta & 0 & 0 & b_{1} \beta \varepsilon & 0 \\
0 & b_{2} \beta & 0 & 0 & b_{1} \beta \varepsilon & 0 \\
0 & 0 & 0 & 0 & 0 & 0 \\
0 & b_{3} \beta & 0 & 0 & b_{3} \beta \varepsilon & 0 \\
0 & b_{4} \beta & 0 & 0 & b_{4} \beta \varepsilon & 0 \\
0 & 0 & 0 & 0 & 0 & 0
\end{array}\right)
$$




$$
V=\frac{\partial v_{i}\left(\sum_{0}\right)}{\partial x_{j}}=\left(\begin{array}{cccccc}
a_{1} & 0 & 0 & 0 & 0 & 0 \\
-a_{7} & a_{2} & -\delta_{1} & 0 & 0 & 0 \\
0 & -\gamma_{1} & a_{3} & 0 & 0 & 0 \\
0 & 0 & 0 & a_{4} & 0 & 0 \\
-\alpha & -\alpha \tau & 0 & -a_{8} & a_{5} & -\delta_{2} \\
0 & 0 & -\alpha & 0 & -\gamma_{2} & a_{6}
\end{array}\right)
$$

dengan $b_{1}=\left(1-p_{1}\right) x_{1}, b_{2}=p_{1} x_{1}, b_{3}=\theta\left(1-p_{3}\right) x_{3}, b_{4}=\theta p_{2} x_{2}+\theta p_{3} x_{3}, a_{1}=\left(1-r_{1}\right)$ $k_{1}+(\alpha+\mu), a_{2}=\left(\gamma_{1}+\alpha \tau+\mu\right), a_{3}=\left(\delta_{1}+\alpha+\mu\right), a_{4}=\left(1-r_{2}\right) k_{2}+\mu, a_{5}=\left(\gamma_{2}+\mu\right)$, $a_{6}=\left(\delta_{2}+\mu\right), a_{7}=\left(1-r_{1}\right) k_{1}$, dan $a_{8}=\left(1-r_{2}\right) k_{2}$.

Nilai bilangan reproduksi dasar dari persamaan (3.1) ditentukan melalui matriks $F V^{-1}$. Selanjutnya nilai eigen dari matriks $F V^{-1}$ diperoleh dengan menyelesaikan $\operatorname{det}\left(F(x) V^{-1}(x)-\lambda I\right)=0$. Dengan demikian diperoleh persamaan karakteristik $\left(\frac{a_{6} \beta \varepsilon\left(a_{8} b_{3}+a_{4} b_{4}\right)}{c_{3} a_{4}}+\frac{a_{3} \beta\left(a_{1} b_{2}+a_{7} b_{1}\right)}{c_{1} a_{1}}+\frac{\beta \varepsilon \alpha\left(a_{1} a_{4} b_{2}+c_{4} b_{1}\right)}{c_{2} a_{1} a_{4}}-\lambda\right) \lambda^{6}=0 \quad$ dan $\quad \lambda=0$ dengan multiplisitas adalah 4. Dari nilai akar-akar tersebut diperoleh spectral radius dari matriks next generation $F V^{-1}$ yaitu $\lambda_{\max }=\frac{a_{6} \beta \varepsilon\left(a_{8} b_{3}+a_{4} b_{4}\right)}{c_{3} a_{4}}+\frac{a_{3} \beta\left(a_{1} b_{2}+a_{7} b_{1}\right)}{c_{1} a_{1}}+\frac{\beta \varepsilon \alpha\left(a_{1} a_{4} b_{2}+c_{4} b_{1}\right)}{c_{2} a_{1} a_{4}}$, selanjutnya $\lambda_{\max }$ disebut sebagai $\mathcal{R}_{0}$. Dengan demikian diperoleh

$$
\mathcal{R}_{0}=\frac{c_{1} c_{2} a_{1} a_{6} \beta \varepsilon\left(a_{8} b_{3}+a_{4} b_{4}\right)}{c_{1} c_{2} c_{3} a_{1} a_{4}}+\frac{c_{2} c_{3} a_{3} a_{4} \beta\left(a_{1} b_{2}+a_{7} b_{1}\right)}{c_{1} c_{2} c_{3} a_{1} a_{4}}+\frac{c_{1} c_{3} \beta \varepsilon \alpha\left(a_{1} a_{4} b_{2}+c_{4} b_{1}\right)}{c_{1} c_{2} c_{3} a_{1} a_{4}},
$$

di mana $c_{1}=\left(a_{2} a_{3}-\delta_{1} \gamma_{1}\right), c_{2}=\left(a_{2} a_{3} a_{5} a_{6}-a_{2} a_{3} \delta_{2} \gamma_{2}+\delta_{1} \gamma_{1} \delta_{2} \gamma_{2}-a_{5} a_{6} \delta_{1} \gamma_{1}\right), c_{3}=$ $\left(a_{5} a_{6}-\delta_{2} \gamma_{2}\right), c_{4}=\left(a_{2} a_{3} a_{6} a_{8}+a_{3} a_{4} a_{6} a_{7}-a_{6} a_{8} \delta_{1} \gamma_{1}+a_{4} a_{7} \delta_{2} \gamma_{1}\right)$.

Kewujudan dan kestabilan titik kesetimbangan endemik maupun non endemik bergantung kepada $\mathcal{R}_{0}$. Nilai $\mathcal{R}_{0}$ pada persamaan (3.10) bergantung pada nilai parameter (3.1). Dengan mudah diketahui bahwa nilai $\mathcal{R}_{0}$ tidak bergantung kepada semua parameter dari model. Untuk menekan terjadinya kondisi endemik, maka kita dapat mengontrol nilai-nilai parameter model yang berpengaruh kepada $\mathcal{R}_{0}$ sehingga nilainya menjadi di bawah satu dan pada kondisi tersebut titik kesetimbangan endemik tidak wujud. Dari persamaan (3.10) diketahui bahwa nilai $\mathcal{R}_{0}$ bergantung kepada parameter yang terkait dengan upaya mencegah penyebaran dan peningkatan jumlah populasi yang terinfeksi Tb yaitu parameter laju kontak infeksi $\mathrm{Tb}$ aktif rentan $\mathrm{Tb}$ yang terkena $\operatorname{Dm}(\beta)$. Nilai $\mathcal{R}_{0}$ juga bergantung kepada laju individu yang terinfeksi Tb tanpa Dm yang berpindah ke kompartemen pemulihan dengan pengobatan $\left(\gamma_{1}\right)$ dan laju individu terinfeksi Tb yang terkena Dm dan berpindah ke kompartemen pemulihan dengan pengobatan $\left(\gamma_{2}\right)$.

Efek dari laju kontak infeksi $\mathrm{Tb}$ aktif rentan $\mathrm{Tb}$ yang terkena Dm dapat diketahui dari perubahan turunan $\mathcal{R}_{0}$ terhadap $\beta$ yaitu,

$$
\begin{aligned}
\frac{\partial \mathcal{R}_{0}}{\partial \beta} & =\left(\frac{a_{6} \varepsilon\left(a_{8} b_{3}+a_{4} b_{4}\right)}{c_{3} a_{4}}+\frac{a_{3}\left(a_{1} b_{2}+a_{7} b_{1}\right)}{c_{1} a_{1}}+\frac{\varepsilon \alpha\left(c_{5} a_{1} a_{4} b_{2}+c_{4} b_{1}\right)}{c_{2} a_{1} a_{4}}\right) \\
& \left(\beta\left(\frac{c_{1} c_{2} c_{3} a_{1} a_{4}}{c_{1} c_{2} a_{1} a_{6} \beta \varepsilon\left(a_{8} b_{3}+a_{4} b_{4}\right)}+\frac{c_{1} c_{2} c_{3} a_{1} a_{4}}{c_{2} c_{3} a_{3} a_{4} \beta\left(a_{1} b_{2}+a_{7} b_{1}\right)}+\frac{c_{1} c_{2} c_{3} a_{1} a_{4}}{c_{1} c_{3} \beta \varepsilon \alpha\left(a_{1} a_{4} b_{2}+c_{4} b_{1}\right)}\right)\right) \\
& =1>0 .
\end{aligned}
$$

Efektivitas pengobatan yang terinfeksi Tb tanpa Dm dapat diketahui melalui perubahan $\mathcal{R}_{0}$ terhadap $\gamma_{1}$ yaitu,

$$
\begin{aligned}
\frac{\partial \mathcal{R}_{0}}{\partial \gamma_{1}}= & \left(\frac{a_{3} \beta b_{1}\left(c_{1}+a_{7}\right)}{c_{1}^{2} a_{1}}+\frac{\beta \varepsilon \alpha\left(\left(a_{6} a_{8}\left(a_{3}-\delta_{1}\right)+a_{4} a_{7} \delta_{2}\right) b_{1} c_{2} a_{1} a_{4}\right)}{c_{2}^{2} a_{1} a_{4}}-\frac{\beta \varepsilon \alpha\left(a_{1} a_{4} c_{5} b_{2}+b_{1} c_{3}\left(a_{3} c_{4}+\delta_{1}\right)\right)}{c_{2}^{2} a_{1} a_{4}}\right) \\
& \left(\gamma_{1}\left(\frac{c_{1} c_{2} c_{3} a_{1} a_{4}}{c_{1} c_{2} a_{1} a_{6} \beta \varepsilon\left(a_{8} b_{3}+a_{4} b_{4}\right)}+\frac{c_{1} c_{2} c_{3} a_{1} a_{4}}{c_{2} c_{3} a_{3} a_{4} \beta\left(a_{1} b_{2}+a_{7} b_{1}\right)}+\frac{c_{1} c_{2} c_{3} a_{1} a_{4}}{c_{1} c_{3} \beta \varepsilon \alpha\left(a_{1} a_{4} b_{2}+c_{4} b_{1}\right)}\right)\right) \\
= & \frac{\gamma_{1}}{\beta}<0 .
\end{aligned}
$$


Sementara efek pemberian pengobatan terinfeksi Tb yang terkena Dm dapat diketahui dari perubahan $\mathcal{R}_{0}$ terhadap $\gamma_{2}$ yaitu,

$$
\begin{aligned}
\frac{\partial \mathcal{R}_{0}}{\partial \gamma_{2}}= & \left(-\frac{a_{6} \beta \varepsilon\left(a_{8} b_{3}+a_{4} b_{4}\right)}{c_{2}^{2} a_{1} a_{4}}+\frac{\beta \varepsilon \alpha \delta_{2} b_{2} c_{2}}{c_{2}^{2} a_{1} a_{4}}-\frac{\beta \varepsilon \alpha\left(\left(c_{5} a_{1} a_{4} b_{2}+c_{4} b_{1}\right) a_{2} a_{1}\left(a_{6}-\delta_{2}\right)+\delta_{1} \gamma_{1}\left(\delta_{2}-a_{6}\right)\right)}{c_{2}^{2} a_{1} a_{4}}\right) \\
& \left(\gamma_{2}\left(\frac{c_{1} c_{2} c_{3} a_{1} a_{4}}{c_{1} c_{2} a_{1} a_{6} \beta \varepsilon\left(a_{8} b_{3}+a_{4} b_{4}\right)}+\frac{c_{1} c_{2} c_{3} a_{1} a_{4}}{c_{2} c_{3} a_{3} a_{4} \beta\left(a_{1} b_{2}+a_{7} b_{1}\right)}+\frac{c_{1} c_{2} c_{3} a_{1} a_{4}}{c_{1} c_{3} \beta \varepsilon \alpha\left(a_{1} a_{4} b_{2}+c_{4} b_{1}\right)}\right)\right) \\
= & \frac{\gamma_{2}}{\beta}<0 .
\end{aligned}
$$

Karena nilai $\frac{\partial \mathcal{R}_{0}}{\partial \beta}>0$ pada kasus penyakit Tb diketahui bahwa semakin besar kontak infeksi terhadap populasi rentan Tb yang terkena Dm maka $\mathcal{R}_{0}$ akan semakin besar sehingga dapat terjadi kondisi endemik. Sebaliknya, karena nilai $\frac{\partial \mathcal{R}_{0}}{\partial \gamma_{1}}<0$ dan $\frac{\partial \mathcal{R}_{0}}{\partial \gamma_{2}}<0$ maka semakin besar pemberian pengobatan pada populasi yang terinfeksi Tb dengan dan tanpa terkena Dm maka nilai $\mathcal{R}_{0}$ akan semakin kecil sehingga suatu kondisi yang pada awalnya endemik dapat berubah menjadi kondisi tidak endemik.

Simulasi dilakukan untuk menunjukkan laju kontak infeksi Tb aktif rentan $\mathrm{Tb}$ yang terkena Dm dan efektivitas pemberiaan pengobatan terhadap infeksi Tb dengan dan tanpa terkena Dm. Model penyebaran penyakit Tb pada penderita Dm pada masing-masing populasi dilakukan dengan memvariasikan parameter yang mempengaruhi model tersebut. Pada Gambar 3.1 diberikan simulasi sistem dengan nilai parameter $\beta=5, \mu=1.5, k_{1}=0.0033$, $k_{2}=0.0047, r_{1}=0, r_{2}=0, \varepsilon=0.8806, \gamma_{1}=1, \gamma_{2}=2, \sigma_{1}=0.05, \sigma_{2}=0.05, \sigma_{3}=0.71$, $\sigma_{4}=0.73, \theta=2, \tau=1.01, \alpha=0.3, p_{1}=0.3, p_{2}=0.6, p_{3}=0.9, \delta_{1}=0.09, \delta_{2}=0.10$ dan $q=0.15$. Nilai parameter kontak infeksi Tb aktif rentan $\mathrm{Tb}$ yang terkena Dm relatif lebih tinggi, sedangkan pengobatan infeksi Tb dengan dan tanpa terkena Dm relatif lebih rendah. Dengan nilai parameter tersebut diperoleh titik kesetimbangan endemik yaitu $\Sigma_{1}=$ $\left(x_{1_{1}}, x_{21}, x_{3_{1}}, x_{4_{1}}, x_{5_{1}}, x_{61}, x_{7_{1}}, x_{8_{1}}, x_{9_{1}}\right)=(0.55,0.04,0.25,0.05,0.02,0.01,0.03$, $0.01,0.04)$ dan diperoleh nilai-nilai eigen $\lambda_{1}=-3.29, \lambda_{2}=-1.01+0.43 i, \lambda_{3}=-1.01-$ $0.43 i, \lambda_{4}=-2.72, \lambda_{5}=-1.49, \lambda_{6}=-2.18, \lambda_{7}=-1.82, \lambda_{8}=-1.94, \lambda_{9}=-1.89$. Karena semua nilai eigen memiliki bagian real yang negatif, maka titik kesetimbangan endemik stabil, artinya penyakit $\mathrm{Tb}$ yang terkena Dm akan menyebar dalam populasi dan terjadi endemik.

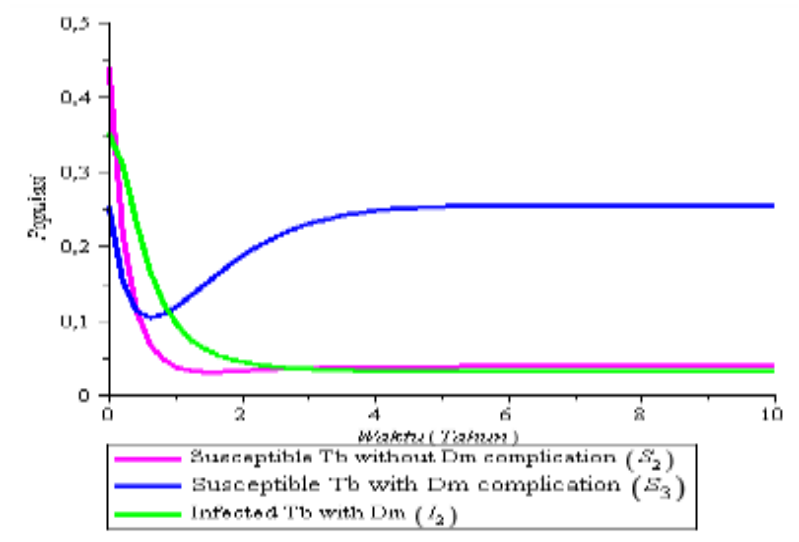

Gambar 3.1. Grafik perubahan populasi Susceptible without Dm complication, Susceptible with Dm complication, dan Infected Tb with Dm terhadap waktu dengan titik kesetimbangan endemik yang stabil.

Gambar 3.1 menunjukkan bahwa individu rentan Tb tanpa komplikasi Dm lebih cepat mewabah atau menuju fase terinfeksi Tb aktif dibandingkan dengan populasi yang rentan $\mathrm{Tb}$ yang komplikasi Dm. Sedangkan individu yang terinfeksi Tb yang terkena Dm menunjukkan jumlah paling rendah dan tidak mengalami peningkatan disetiap tahunnya. 
Nursamsi, Syamsuddin Toaha, Kasbawati

Selanjutnya, diberikan simulasi dengan mengurangi nilai parameter kontak infeksi $\mathrm{Tb}$ aktif rentan $\mathrm{Tb}$ yang terkena Dm dengan meningkatkan nilai parameter pengobatan $\mathrm{Tb}$ dengan dan tanpa terkena Dm. Nilai parameter $\beta=4, \mu=1.5, k_{1}=0.0033, k_{2}=$ $0.0047, r_{1}=0, r_{2}=0, \varepsilon=0.8806, \gamma_{1}=1, \gamma_{2}=10, \sigma_{1}=0.05, \sigma_{2}=0.05, \sigma_{3}=0.71, \sigma_{4}=$ $0.73, \theta=2, \tau=1.01, \alpha=0.3, p_{1}=0.3, p_{2}=0.6, p_{3}=0.9, \delta_{1}=0.09, \delta_{2}=0.10, q=0.15$. dengan nilai parameter tersebut diperoleh titik kesetimbangan non endemik yaitu $\Sigma_{0}=$ $\left(x_{1_{0}}, x_{2_{0}}, x_{3_{0}}, x_{4_{0}}, x_{5_{0}}, x_{6_{0}}, x_{7_{0}}, x_{8_{0}}, x_{9_{0}}\right)=(0.60,0.047,0.35,0,0,0,0,0,0)$ dan seterusnya diperoleh nilai-nilai eigen $\lambda_{1}=-1.50, \lambda_{2}=-1.90, \lambda_{3}=-2.50, \lambda_{4}=-9.46, \lambda_{5}=$ $-2.18, \lambda_{6}=-1.81, \lambda_{7}=-1.34, \lambda_{8}=-1.65$, dan $\lambda_{9}=-1.51$.

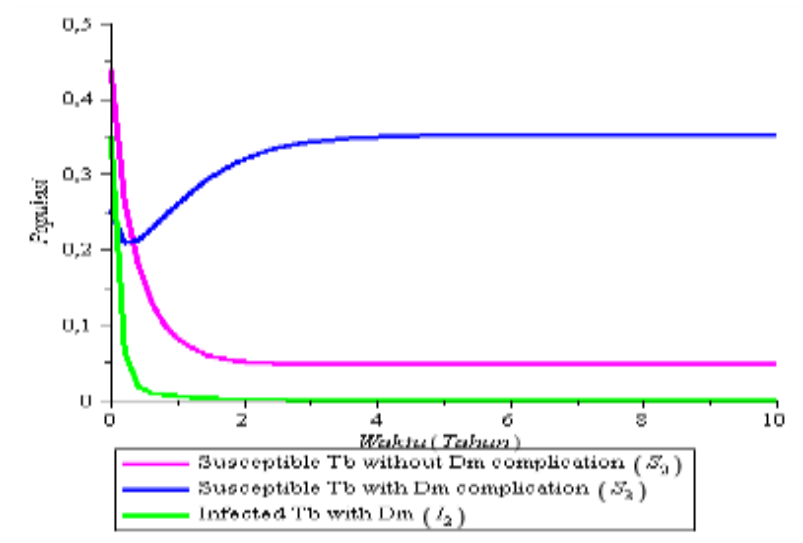

Gambar 3.2. Grafik perubahan populasi Susceptible without Dm complication, Susceptible with Dm complication, dan Infected Tb with Dm terhadap waktu dengan titik kesetimbangan non endemik yang stabil.

Gambar 3.2 menunjukkan bahwa dengan bertambahnya waktu maka jumlah $S_{2}, S_{3}$ dan $I_{2}$ akan semakin berkurang dan konvergen ke titik kesetimbangan bebas penyakit. Namun membutuhkan waktu yang lama untuk menuju ke titik kesetimbangan bebas penyakit.

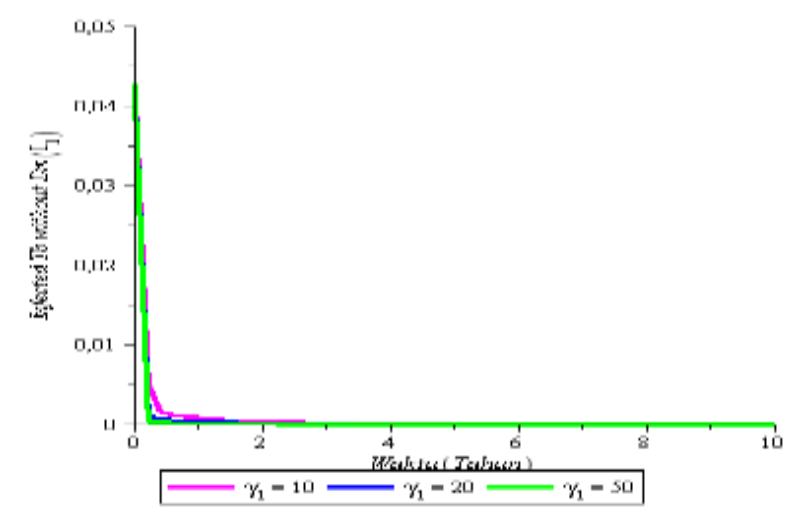

Gambar 3.3. Grafik perubahan populasi Infected $\mathrm{Tb}$ without $\mathrm{Dm}\left(I_{1}\right)$ terhadap waktu dengan titik kesetimbangan non endemik stabil. 


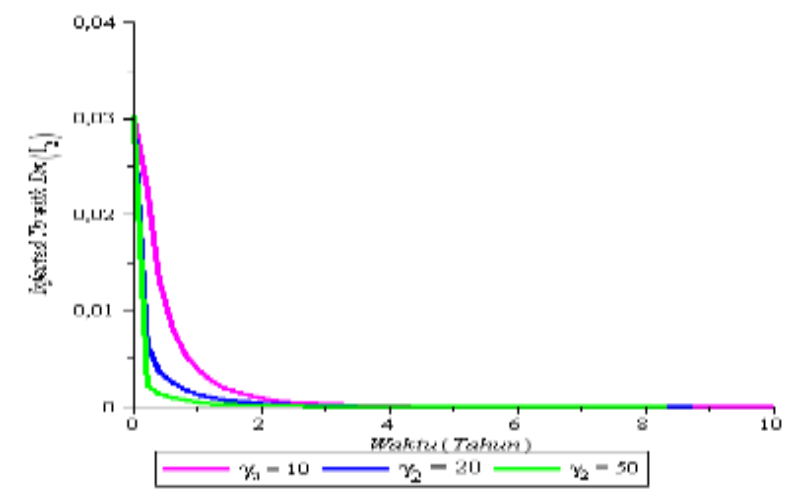

Gambar 3.4. Grafik perubahan populasi Infected $\mathrm{Tb}$ with $\mathrm{Dm}\left(I_{2}\right)$ terhadap waktu dengan titik kesetimbangan non endemik stabil.

Efektivitas pemberian pengobatan infeksi Tb aktif dengan dan tanpa Dm dapat dilihat pada Gambar 3.3 dan ditunjukkan bahwa jika nilai parameter ditingkatkan, maka ukuran populasi infeksi Tb aktif tanpa Dm $\left(I_{1}\right)$ akan semakin berkurang. Hal ini menunjukkan bahwa populasi akan terbebas dari penyakit. Sementara dari Gambar 3.4 diketahui bahwa populasi infeksi Tb aktif yang terkena Dm $\left(I_{2}\right)$ akan konvergen ke titik kesetimbangan bebas penyakit untuk jangka waktu yang cukup lama.

\section{Kesimpulan}

Dari hasil analisis dan simulasi yang diberikan dapat disimpulkan bahwa model penyebaran penyakit tuberkulosis pada penderita diabetes mellitus dengan faktor pengobatan diperoleh dua titik kesetimbangan yaitu non endemik $\left(\Sigma_{0}\right)$ dan endemik $\left(\Sigma_{1}\right)$. Kewujudan dan kestabilan kedua titik kesetimbangan tersebut dipengaruhi oleh nilai $\mathcal{R}_{0}$. Berdasarkan nilai $\mathcal{R}_{0}$, diperoleh beberapa parameter yang berpengaruh yaitu parameter infeksi Tb aktif rentan Tb yang terkena $\operatorname{Dm}(\beta)$, pengobatan infeksi Tb tanpa terkena $\operatorname{Dm}\left(\gamma_{1}\right)$, dan pengobatan infeksi Tb yang terkena Dm $\left(\gamma_{2}\right)$. Jika diberikan nilai parameter $\beta$ tinggi, $\gamma_{1}$ dan $\gamma_{2}$ lebih rendah maka $\mathcal{R}_{0}>1$ yang artinya kondisi endemik masih terjadi. Sebaliknya, jika diberikan nilai parameter $\beta$ lebih rendah, $\gamma_{1}$ dan $\gamma_{2}$ lebih tinggi maka $\mathcal{R}_{0}<1$ yaitu kondisi menjadi non endemik.

Dari simulasi yang diberikan diketahui bahwa dengan menaikkan pemberian pengobatan infeksi Tb aktif tanpa Dm yaitu $\gamma_{1}=10$, dan pengobatan infeksi Tb aktif yang terkena Dm yaitu $\gamma_{2}=10$, maka kondisi endemik dapat berubah menjadi kondisi non endemik. Hal ini menunjukkan bahwa pemberian pengobatan infeksi Tb aktif dengan dan tanpa terkena Dm berpengaruh terhadap penyebaran penyakit tuberkulosis.

\section{Daftar Pustaka}

[1] Wiraningsih, E.D., Aryati, W. L., Toaha, S. \& Lenhart, S. (2010). Optimal control for SEIR rabies model between dogs and human with vaccination effect in dogs. Proceedings of the 6th IMT-GT Conference on Mathematics, Statistics and its Applications (ICMSA2010) Universiti Tunku Abdul Rahman, Kuala Lumpur, Malaysia. Vol. 6. 1161-1175

[2] Wiraningsih, E. D., Agusto, F., Aryati, L., Lenhart, S., Toaha, S., Widodo \& Govaerts, W. (2015). Stability analysis of rabies model with vaccination effect and culling in dogs. Applied Mathematical Sciences, 9(77), 3805-3817. doi:10.12988/ams.2015.53197

[3] Beay, L., Kasbawati \& Toaha, S. (2017). Effects of human and mosquito migrations on the dynamical behavior of the spread of malaria AIP Conference Proceeding 1825, 020006.http://doi.org/10.1063/1.4978975

[4] Hartati, H., Toaha, S. \& Kasbawati (2019). Stability analysis of SEISEIR-SEI modelling on the dynamics of spread dengue fever with vaccination and insectiside. $J$. Phy.: Conf. Ser. 1341 062033. doi:10.88/1742-6596/1341/6/062033 
[5] Muin, R. M., Toaha, S \& Kasbawati (2019). Effect of vaccination and treatment on the MSEICR model of the transmission of hepatitis B virus. J. Phys.: Conf. Ser. 1341062031. doi: 10.1088/1742-6596/1341/6/062031

[6] Crofton, S. J. (2009). Crofton's Clinical Tuberculosis Third Edition. Oxford: Macmillan Publishers Limited.

[7] Sembiring, S. (2019). Indonesia Bebas Tuberculosis. Jawa Barat: CV Jejak.

[8] Wulandari, D. R., \& Yani, J. S. (2013). Diabetes mellitus dan permasalahannya pada infeksi tuberkulosis. J Respir Indo, Vol.33, No.2

[9] Soewondo, P. (2007). Hidup Sehat dengan Diabetes. Jakarta: FKUI.

[10] Restrepo., Camerling, A. J., Rahbar, M. H., Wang, W., Restrepo, M. A., Zarate, I., Mora-Guz'an, F., Crespo-Solis, J. G., Briggs, J., Mc Cormika, J. B., \& Fisher-Hocha, S. P. (2011). Cross-sectional assessment revels high diabetes prevalence among newly diagnosed tuberculosis cases. Bulletin of The World Health Organization, 89 (5): 352359. doi:10.2471/BLT.10.085738359.

[11] Moualeu, D. P., Bowong, S., Tewa, J. J., \& Emvudu, Y. (2012). Analysis of the impact of diabetes on the dynamical transmission of tuberculosis. Math. Model. Nat. Phenom., Vol. 7. 117-146. doi:10.1051/mmnp/20127309.

[12] Danumjaya, P., \& Merina, D. (2019). Stability preserving non standard finite difference schemes for diabetes with tuberculosis infectious model. Letter in Biomathematics. doi:10.1088/23737867.2019.1618743.

[13] Murray, J. D. (2012). Mathematical Biology I. An Introduction (Third Edition ed.). New York, USA: Springer.

[14] Willems, J. L. (1970). Stability Theory of Dynamical System. London: Thomas Nelson $\&$ Sons.

[15] Toaha, S. (2013). Pemodelan Matematika dalam Dinamika Populasi. Makassar: Dua Satu Press.

[16] Driessche. \& Watmough. (2002). Reproduction numbers and sub-threshold endemic equilibria for compartmental models of disease transmission. Mathematical Biosciences. Vol. 2002, No. 180, hal. 29-48. 